\title{
Palaeostructure, evolution and tight oil distribution of the Ordos Basin, China
}

\author{
Shengli Gao ${ }^{1, *}$, and Jinxia Yang ${ }^{2}$ \\ ${ }^{1}$ Xi'an Shiyou University, Xi'an, 710065 Shaanxi, China \\ ${ }^{2}$ School of Mathematics and Information Science, Shaanxi Normal University, Xi'an, 710062 Shaanxi, China
}

Received: 11 August 2018 / Accepted: 15 February 2019

\begin{abstract}
Whether or not the tight oil in the Triassic Yanchang Formation of the Ordos Basin is controlled by structural factors is a controversial issue, the relationship between the structural factors of the strata and the distribution of tight oil is limited to the study of current structures. The traditional view is that structural factors have no obvious control over the formation and distribution of the oil reservoir. Taking the Chang 8 member of the Triassic Yanchang Formation in the Ordos Basin as an example, this paper studies respectively the burial of strata-hydrocarbon generation history of the individual well and the structural evolution history of strata in the basin by using software tools of the Genex burial-hydrocarbon generation history restoration and TemisFlow evolution of stratigraphic structures. It is considered that the hydrocarbon generation period of the source rock of the Triassic Yanchang Formation in the Ordos Basin is from early Middle Jurassic to end of Early Cretaceous. By reconstructing the evolution and structure of the Chang 8 member during the hydrocarbon accumulation period, combined with a comprehensive analysis on the distributional characteristics of the Chang 8 oil reservoir, we found the palaeoslopes and palaeohighs of the Chang 8 reservoir to represent areas in which tight oils were distributed. Palaeo-structural characteristics of the target layer exhibit control over the Chang 8 reservoir. The new theory underlying tight oil exploration, which is based on the recovery of the palaeogeomorphology of the target layer during the hydrocarbon generation period, incorporates the vital roles of key controlling factors over tight oil accumulation, so that the mind-set on tight oil exploration in the Ordos Basin has evolved.
\end{abstract}

\section{Introduction}

The exploration of tight oil in the Ordos Basin has been aimed at the deep water zone. The search for a zone for high-quality reservoir development and the sweet spot of the tight oil reservoir remains in the exploration stage, and will be the key research direction to pursue in the future. Current studies on the factors controlling tight oil accumulation are mostly based on comprehensive analyses of various geological factors, among which structural factors have gradually attracted the attention of researchers. This change also reflects the fact that researchers have been focused on discerning the distributions of the high-quality reservoirs and the sweet spots of tight oil reservoirs. Regarding the factors controlling oil accumulation, most researchers believe that the high-quality hydrocarbon source rock of the 7th segment of the Yanchang Formation in the Ordos Basin is the major hydrocarbon generation layer in the basin.

\footnotetext{
* Corresponding author: gshl@xsyu.edu.cn
}

In settings over large distributional areas and with source reservoir contact, reservoir formation and distribution are mostly controlled by sedimentary microfacies and the physical properties of the reservoir (Ren et al., 2014; Yang et al., 2017) or by the hydrocarbon source and reservoir (Zhao et al., 2012). The evolution of the thermal structure of the basin, especially structural thermal events during the Mesozoic, exhibits an important control over oil accumulation (mineralization) (Gao and Ren, 2006; Ren et al., 2014, 2017). What should be emphasized in particular, is that the controlling effect of tectonism on the formation and distribution of the tight oil reservoir in the Triassic Yanchang Formation has increasingly attracted attention of researchers, and the traditional theories applied to this reservoir have gradually changed. Early researchers ignored the effects of structural factors on the accumulation of tight oil. For many years, researchers focused on current structural characteristics; based on the traditional mind-set that "the slope in northern Shaanxi is a gentle west-inclined monocline with simple structure, and lacks structural traps such as anticline", it has been assumed that the formation and distribution of oil reservoirs are dominantly controlled 
by their sedimentary facies, while other factors, including structure, impart no control over the formation and distribution of reservoirs in the Yanchang Formation (Yang et al., 2007, 2013). With the notable increase in drilling density, the uplifted structure of the Yanchang Formation, especially the low-amplitude, nose-shaped uplifted structure, has been found to be more developed than previously thought, and it has substantial control over the formation and enrichment of Triassic oil reservoirs (Zhao et al., 2006). However, these structural characteristics refer to the present structure after the accumulation period. What were the structural characteristics during the accumulation period? How did those structural characteristics evolve and become retained as the current ones? How were the structures during the accumulation period (i.e., the tectonic geomorphology of the bottom of the lake basin) and the period of oil and gas charging formed? These were unknown in the past, and there have been limited studies more recently.

In a word, the control factors of tight oil accumulation need further investigation (Hu et al., 2016; Yao et al., 2013; Yang et al., 2017). Few studies have been conducted on the control of the formation and distribution of tight oil by the paleostructure during hydrocarbon filling and accumulation. Recently, the role of structural conditions in controlling hydrocarbon accumulation is emphasized (Guo, 2010). In this paper, the relationship between stratigraphic structural features and tight oil distribution in the reservoir forming period is revealed through the restoration of paleotectonics in the Chang 8 Formation of the Triassic system.

With the acceleration of tight oil exploration, the discovery of the Chang 6 and Chang 8 oil reservoirs in the Huaqing region of the Ordos Basin has attracted attention to the control of structural factors (i.e., the geomorphology of bottom of the lake basin) throughout the oil reservoir. The sedimentary periods of target layers in the Chang 6 and Chang 8 reservoirs are in a deep to somewhat deep lake environment. Based on conventional exploration theories, this area is a "forbidden zone" for tight oil exploration. In-depth studies have suggested that the sedimentary period of the Chang 6 oil-bearing formation in this area included the large-scale development of a delta. Large-scale, low-permeability reservoirs were formed under the joint control of favourable sedimentary facies and diagenetic facies, and the setting of a multi-slope break bottom geomorphology of the lake basin was the structural condition needed for the formation of the reservoirs (Yang et al. 2012). Focusing on the important role of structural factors during the formation of tight oil makes it possible to directly search for and evaluate the sweet spots of tight oil. Exploring tight oil in the "deep water zone" is accelerated (Bai et al., 2017; Xu et al., 2016).

\section{Geological setting}

The Ordos Basin is located in central western China, and echoes the Jinxi Flexure Belt and the Luliang Uplift in the east. In the west, it stands opposite to the Liupanshan and Yinchuan basins through a thrust structural belt.
In the south, it faces the Weihe Basin across from the Weibei Flexure Belt. In the north, it is adjacent to the Hetao Basin from across the Wulinger bulge, and it has a rectangular outline. The overall structural form of the basin presents as a north-south, rectangular basin, composed of a large, asymmetrical syncline, with a wide and gentle eastern wing, a steep and narrow western wing, and an area of $25 \times 10^{4} \mathrm{~km}^{2}$ (He, 2003; Lai et al., 2016).

Before the late Triassic, the Ordos Basin was part of the western margin of the North China Platform, inheriting and developing the Palaeozoic ocean-land phases of continental sedimentation. In the late Triassic, due to compression from west to east and the left-lateral shearing of the western margin of the North China Platform, the platform basement in the Ordos Basin was bent downward during the unbalanced uplift and subsidence. The southern region, which had continuously been a depression over a long period of time, gradually began separating from the North China Platform, until it evolved into an independent, large, inland lacustrine basin. During the Indosinian Orogeny at the end of the Late Triassic, the basin rapidly rose, and this lake basin disappeared and was denuded. During the Jurassic, the basin began to sink again, developing a broad distribution of flood plain deposits. By this time, within the $25 \times 10^{4} \mathrm{~km}^{2}$ area of the main body of the Ordos Basin, the structural and sedimentary evolution provided the time, space and abundant material needed for the formation, migration and accumulation of Mesozoic oils. After the Early Cretaceous, the basin began to uplift and the overlying strata in local areas suffered from denudation. Since then, it has been maintained as the current structural features.

The basin can be divided into six first-class structural units, namely the central Yishan Slope, the eastern Jinxi Flexure Belt, the western Tianhuan Depression, the western marginal thrust belt, the northern Yimeng Uplift and the southern Weibei Uplift (Fig. 1). Fractures and folds along the edge of the basin are relatively well-developed (He, 2003), while the internal structure of the basin is comparatively simple; the strata are gently sloping by generally less than $10 \mathrm{~m} / \mathrm{km}$. There is no secondary structure on the Yishan Slope, and the tertiary structure is mostly composed of nose-shaped folds, anticlinal structural developments, with large amplitudes and relatively good traps are rarely found.

According to the drilling and seismic data in the study area, the cross section was made. In the Ordos Basin, the oldest strata revealed by drilling are Proterozoic strata (Pt) (Fig. 1c). Most of the Yishan Slope was formed during the Early Cretaceous. Presenting as a gentle single slope inclined to the west, with an inclination angle of only $0.5^{\circ}-1^{\circ}$, and the stratigraphic thickness varies little (Figs. 1c and 2). Nose-shaped uplifts of different scales and sizes, and tilting from east to west, are developed along the slope belt.

The Chang 8 oil layer is one of the major oil layers of the Triassic Yanchang Formation in the Ordos Basin. The Yanchang Formation is divided into five members according to the sedimentary sequence, and further divided into 10 oil layers from top to bottom, according to the vertical 

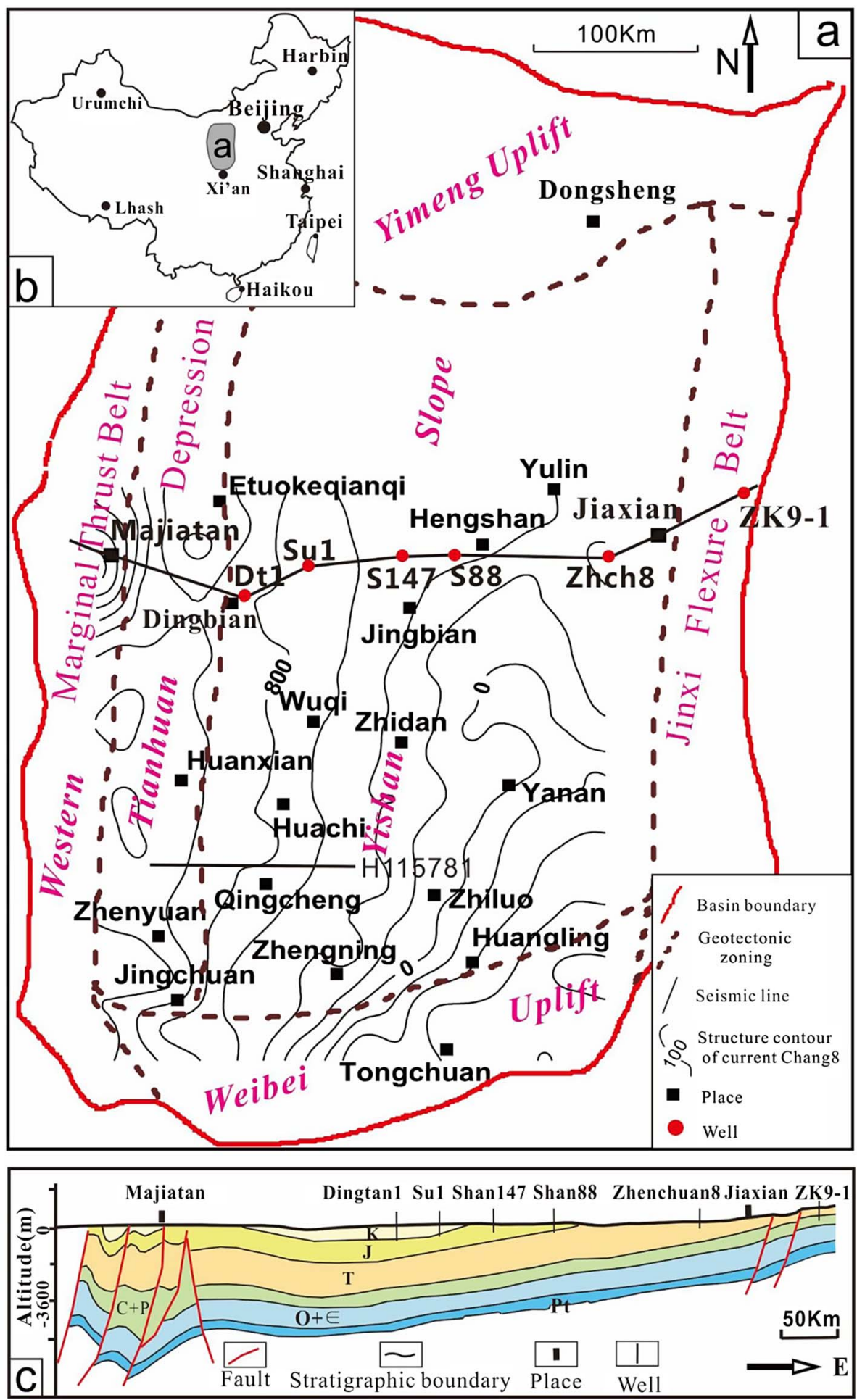

Fig. 1. (a) Location of the Ordos Basin in China; (b) Tectonic units in the Ordos Basin; (c) Stratigraphic correlation profile of Majiatan-Zk9-1.

distribution of the oil layers. Namely, these layers are the Chang 1 to Chang 10, among which, Chang 1, Chang 2, Chang 3, Chang 6 and Chang 8 are regional industrial oil layers (Fig. 3).
The Ordos Basin was developed in the Late Triassic of the Mesozoic. During this period, the Ordos prototype basin was part of the North China ancient land (Ye, 1983). It was formed under the background of Caledonian and Variscan 


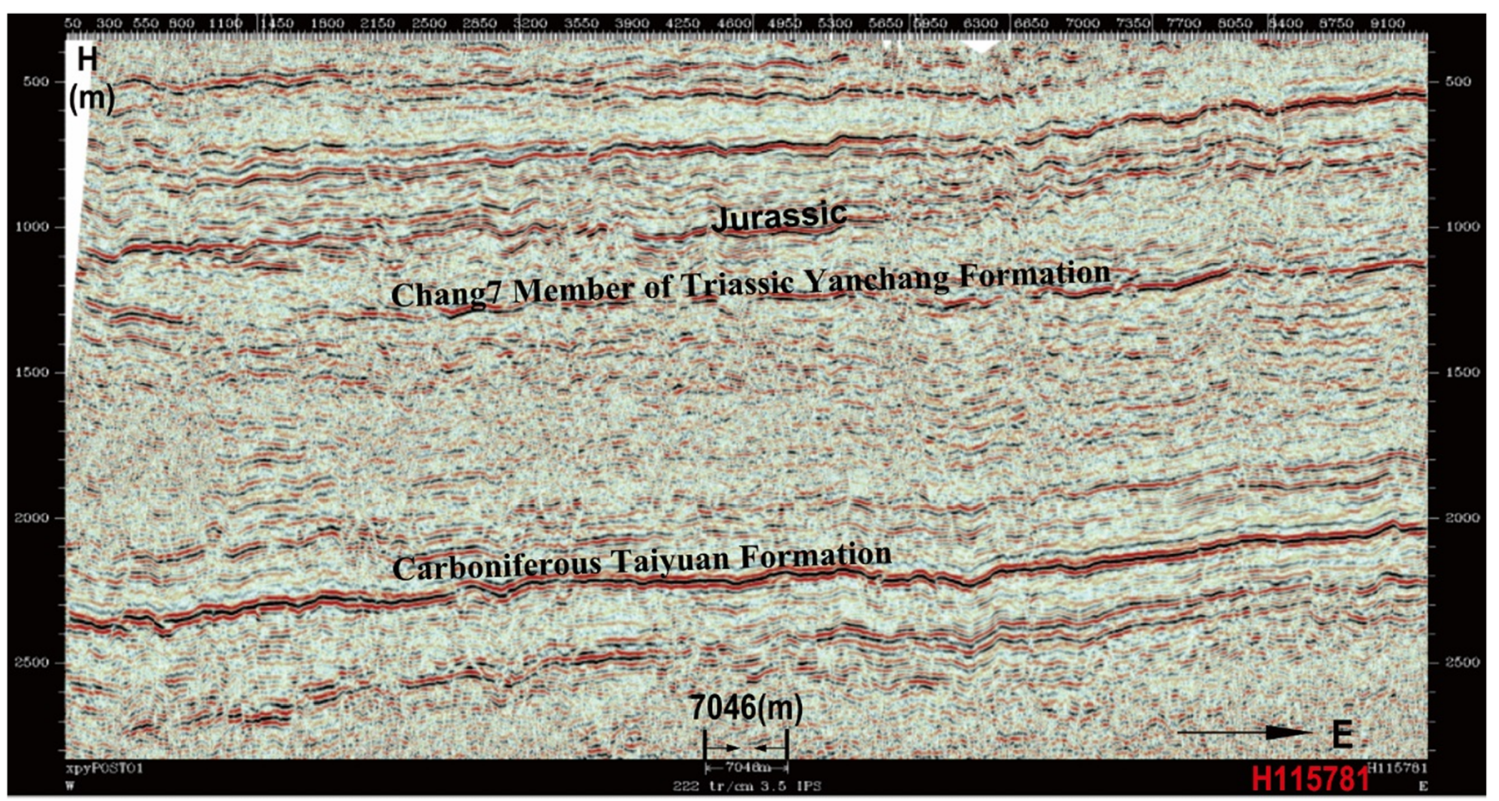

Fig. 2. Two-dimensional seismic profile of the H115781 in the Ordos Basin, China (See Fig. 1a for the position of seismic line).

tectonic movements reforming the North China ancient land and through the multi-stage reformation of Indochina movement and Yanshan movement (Fig. 4).

To the south of the prototype basin in Late Triassic was the Qilian-North Qinling Caledonian fold belt formed in the Caledonian period, with compression direction of northwest, and the Kunlun-Qinling Variscan-Indosinian fold belts formed in Variscan-Indosinian movement period, with compression direction of northwest. To the north of the prototype basin is the Tianshan-Xingmeng Variscan fold belt formed in the Variscan period, with compression direction of northwest, and the Alxa ancient land in the Yinshan mountain system and the northwest region of Ordos Basin. To the east is a large piece of North China ancient land.

The mainly eastward subduction occurred in the northwest of the North China ancient land, under the influence of the Paleotethys in the Late Triassic (Indosinian period) and acted on the Alxa ancient land. In this period (Indosinian), the North China ancient land still had the northeastward compressive force acting on the Qilian-North Qinling fold belt because of the impact of the Yangtze plate tectonic activity. Under the combined action of the forces in the two directions mentioned above, the push-eastward occurred, and a foreland basin was formed in the western part of the Ordos Basin due to the subduction.

During the Indosinian-Yanshanian period, the China plate was affected by the Tethys and Pacific plate activities. The force acting on the North China paleo-continent is mainly represented by the westward compression stress. Affected by this stress, the North China ancient land gradually uplifted from east to west, forming the structural features of the Yanchang Formation strata in the Ordos Basin, which are "high in the east and low in the west". From the Late Cretaceous to the Early Tertiary, the stress of westward compression gradually weakened and disappeared. Finally, the present Ordos Basin was formed, basically being a large westward inclined monoclinic structure, constituting a structural feature from high to low eastto-west, with a depression-thrust belt in the western part of the basin (Liu et al., 1986; Sun et al., 1985; Ye, 1983).

\section{Materials and methods}

A geological model of the basin was established based on a systematic sorting of various data, such as structural, sedimentary, mud logging and well logging data in the study area, with the palaeo-surface morphology, erosion thickness and compaction coefficients taken into account. Simulation parameters were selected, and the initial and boundary conditions were defined, which provided a basis for recovering the evolutionary processes at work in the basin and the evolutionary history of regional fluid dynamics. The Temis3D v.4.0 and Temis2D v.4.0.4 basin simulation software developed by the French Petroleum Research Institute was used to recover the post-hydrocarbon structure and evolution of the target layers in the Chang 8 reservoir (Including plane and profile features). With the distributional characteristics of the Chang 8 reservoir taken into consideration, a study on the control of the bottom palaeostructure and the evolution of the target layers of the tight oil reservoir was conducted.

Genex v. 4.0.3 burial history recovery software was used to recover the single-well burial and hydrocarbon generation histories.

When applying the TemisFlow basin simulation software to recover the evolution of the palaeostructure, the major parameters involved were the mudstone compaction coefficient, erosional thickness, stratigraphic thickness, sand-to-ground ratio and the structure of the top surface 


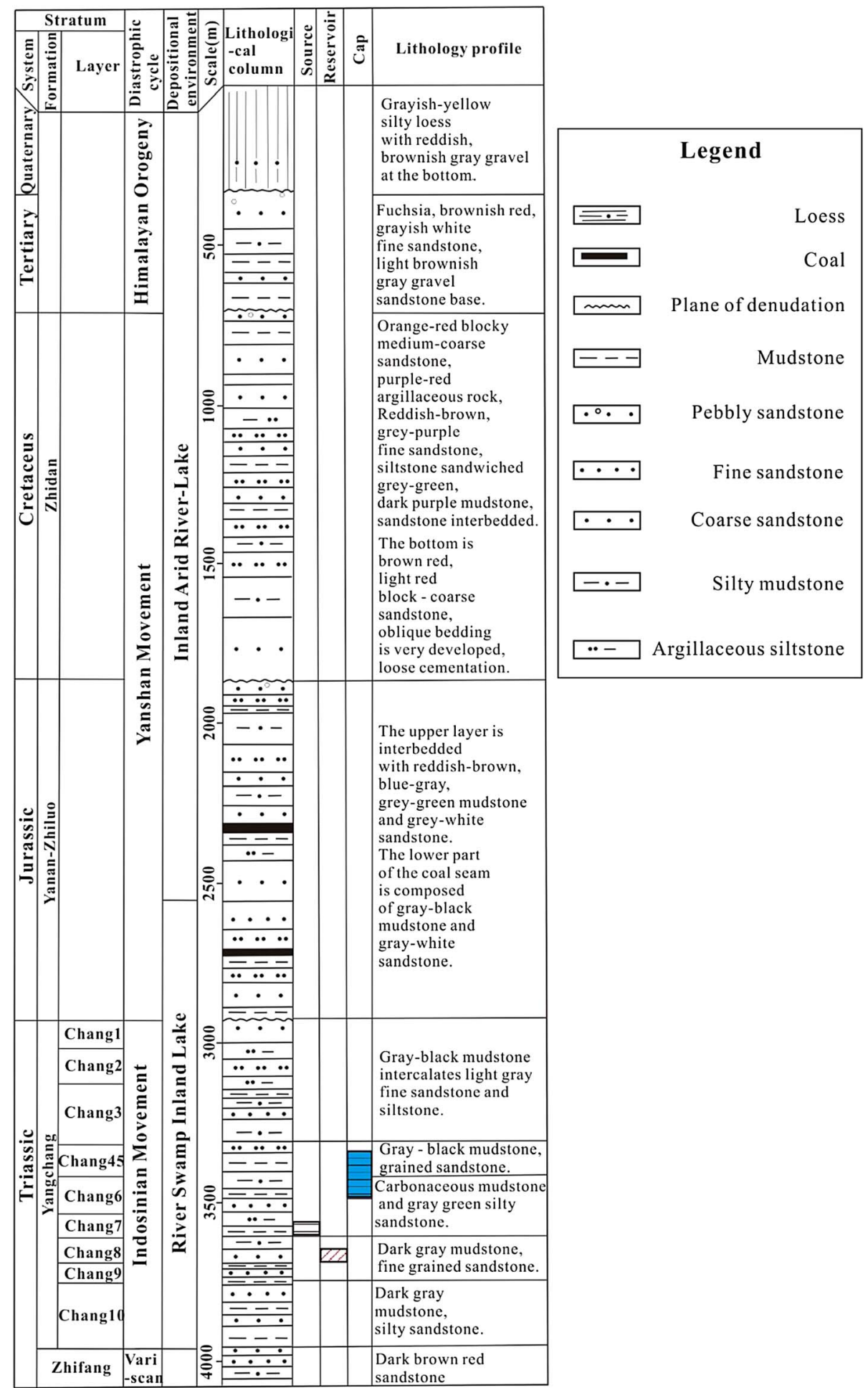

Fig. 3. Formation table and comprehensive stratigraphic column in the Ordos Basin.

structure. Acquisition of these parameters was based on the logging curves of many petroleum exploration wells in the study area, and the sonic wave time difference curve was used to recover the mudstone compaction coefficient and the erosional thickness, while the acquisition of the stratigraphic thickness, sand-to-ground ratio and top surface structural characteristics was achieved by a comprehensive application of logging curves, such as those for sonic wave time difference, electric resistivity and density. In the process of palaeo-structural simulations, the acquisition of 


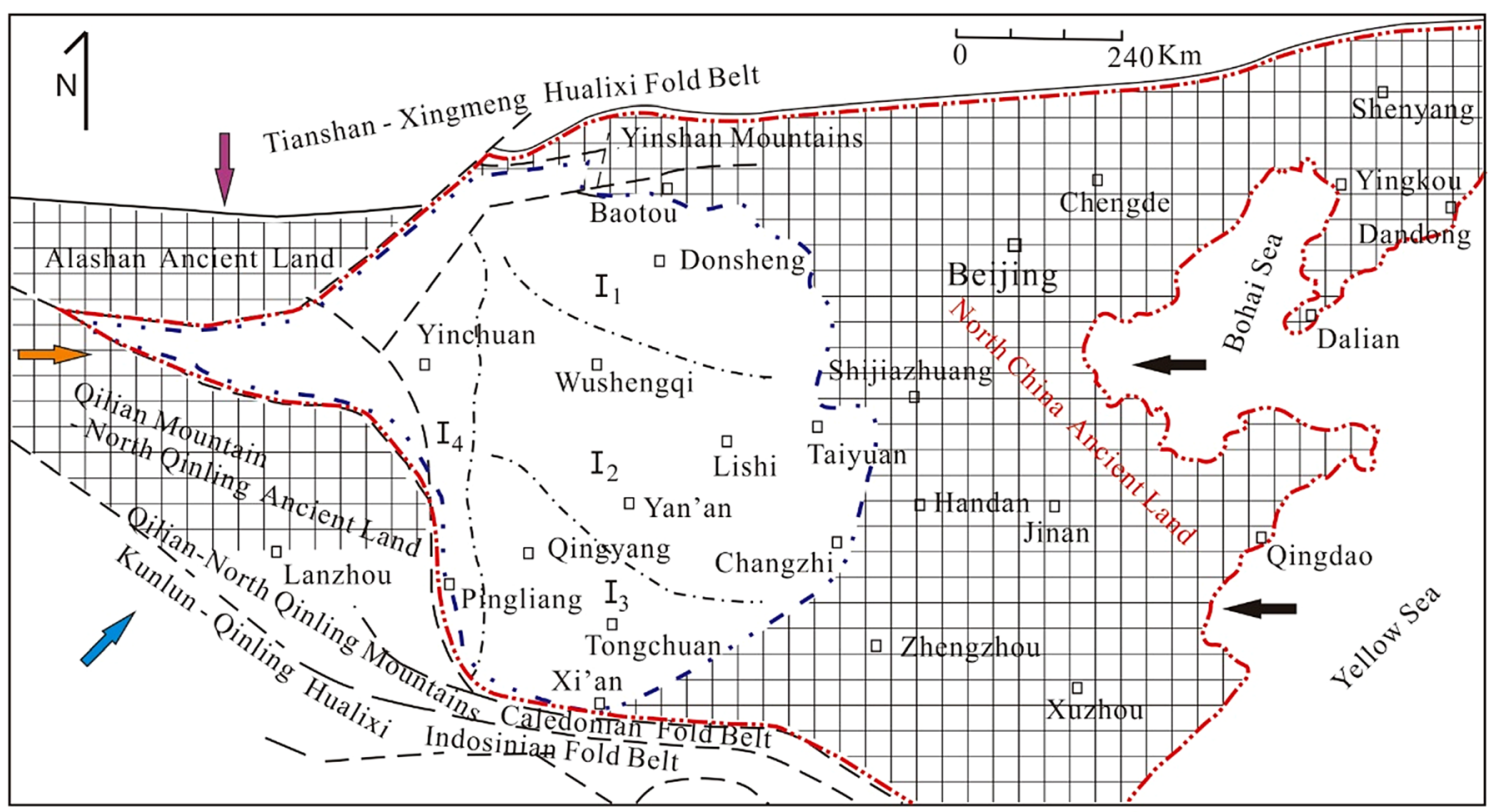

Legend

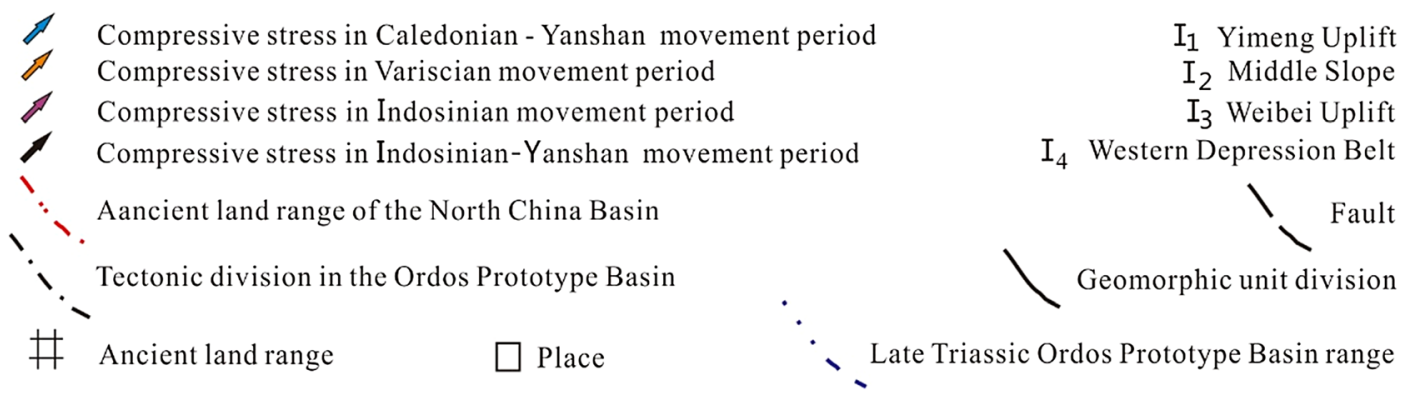

Fig. 4. The geodynamic setting of the development of Late Triassic in the Ordos Basin, China (modified from Ye, 1983; Sun et al., 1985; Liu et al., 1986).

other simulation parameters, such as the hydrocarbon generation kinetic parameter and temperature field parameter, were conducted by referring to previously published research. Other researchers have previously conducted many studies on the geothermal field and its evolution in the Ordos Basin, and have made many important discoveries. After recovering the bottom structure and evolution of the target layers of the Chang 8 reservoir after the hydrocarbon period, the distribution of Chang 8 oil reservoirs that have been discovered in the basin were also taken into consideration. Subsequently, the bottom palaeostructure and evolution of the Chang 8 reservoir, as well as the distribution of tight oils, were revealed.

Abundant $\log$ data of interval transit times were applied, the overpressure of the individual wells were calculated and a plane distribution map was drafted. Meanwhile, abundant drilling data were used to produce a sand-ground ratio distribution map of the Chang 8 member. Comprehensive analyses were performed on the tectonic migration and accumulation conditions of the sand body by combining the evolutionary characteristics of the structure of tie well
C9-Jt600, revealing the evolutionary characteristics of the target strata.

\section{Results}

TemisFlow basin simulation software was used to reconstruct the structure of the target layers of the Chang 8 reservoir and their evolution after the hydrocarbon generation period, comprehensive basin burial-hydrocarbon generation history analysis, in order to reveal the intrinsic coupling between the palaeostructure and evolution of the target layer during the hydrocarbon generation period and the distribution of the oil reservoir.

\subsection{Reconstruction of the burial history and thermal evolution of hydrocarbon source rocks of a single well}

The results showed that the hydrocarbon source rock of the Triassic Yanchang Formation reached the hydrocarbon generation threshold in the Early Cretaceous, and entered 


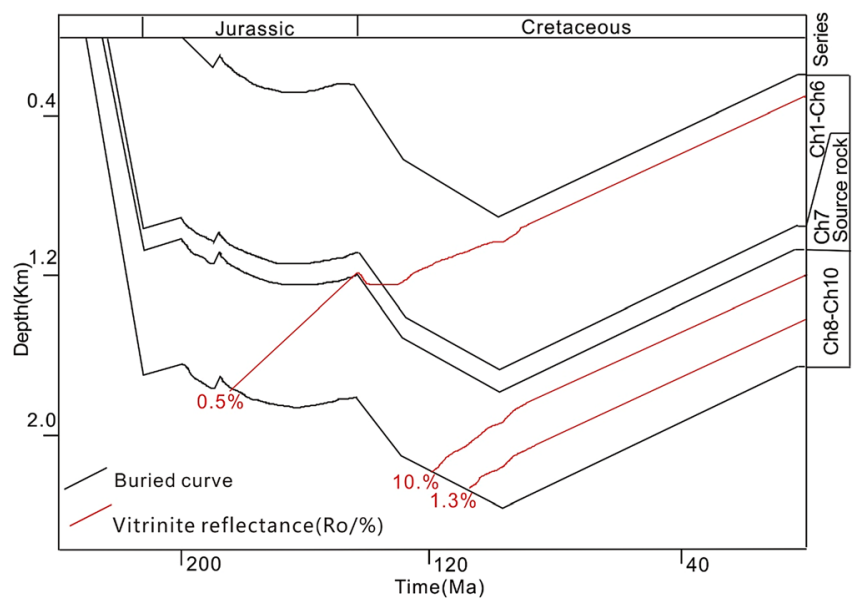

Fig. 5. Single well burial history and hydrocarbon generation history restoration of $\mathrm{Y}_{-} 1$ well.

the peak period of oil generation by the end of the Early Cretaceous. By this time, major lithologic traps and structural-lithologic composite traps in the basin had also been formed; after the Early Cretaceous, the basin overall was uplifted, and no large fault systems were formed inside the basin. Therefore, the Mesozoic low-permeability and ultra-low permeability reservoirs, especially the fluids in the Yanchang Formation reservoirs, effectively remained in a closed environment, so the gas and oil reservoirs that had been formed were well preserved (Fig. 5).

\subsection{Late Middle Jurassic tectonic geomorphology of concave and convex structures of plane distribution characteristics at the base of Chang 8}

At the end of the Middle Jurassic, the bottom structure of the Chang 8 reservoir evolved into a structural pattern that was high in the south and southeast and low in the north and northwest. In the south-eastern part of the basin, there were three large convex belts extending from northwest-southwest. The convex belts in the southeast and southwest were large, while the convex belt in the south central region was relatively small. The difference in the elevation of the convex belt in the southwest was $>860 \mathrm{~m}$, that in the southwest $>900 \mathrm{~m}$ and in the south central part, it was $>300 \mathrm{~m}$. Large areas of the central and north-western parts of the basin were depression zones, among which some partially low-amplitude, nose-shaped convexes were developed (Fig. 6). It can be seen from Figure 4 that the Chang 8 reservoir is almost completely distributed in the Late Jurassic convex region in the southwest.

\subsection{Early Cretaceous tectonic geomorphology of concave and convex structures of plane distribution characteristics at the base of Chang 8}

At the end of the Early Cretaceous, the overall geomorphology of the base of the Chang 8 reservoir presented a

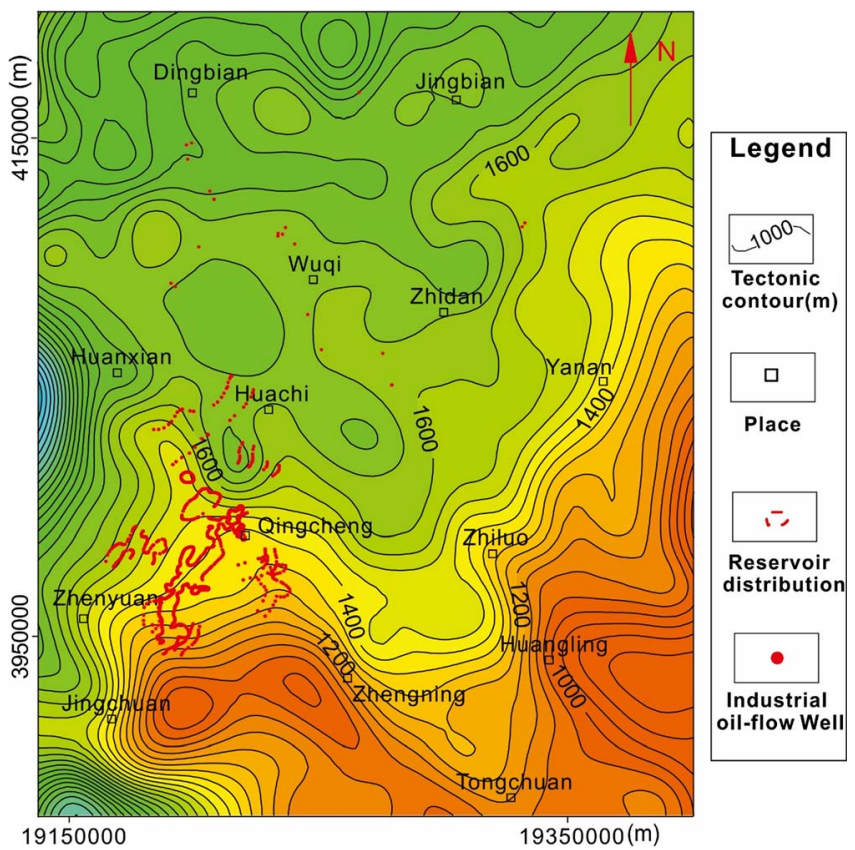

Fig. 6. Structural morphology of Chang 8 member bottom at the end of the Middle Jurassic and reservoir distribution of the Ordos Basin.

structural pattern of high in the east and northeast and low in the west and southwest. Compared with the bottom structure of the Chang 8 reservoir at the end of the Middle Jurassic, an obvious inversion in tectonic movement had occurred. Overall, four large and small convex belts that converged toward the north-western part of the basin developed. Three convex belts in the south central region extended approximately along a northwest-southeast direction, and the northern part extended approximately from west-east. The difference in the elevations of the southwestern area and the northern part of the basin was $>300 \mathrm{~m}$. The eastern part of the basin and the area between the two convex belts in the south-eastern part of the basin were depression belts, among which a large depression was distributed across the eastern part of the basin, extending from north-south. The Early Cretaceous concave and convex tectonic features of the Chang 8 sub-face were generally inherited from tectonic features developed in the Middle Jurassic. It also can be concluded from Figure 4 that the Chang 8 reservoir is dominantly distributed across the southwestern convex region in the Early Cretaceous basin (Fig. 7).

\subsection{Current tectonic geomorphology of concave and convex structures of plane distribution characteristics at the base of Chang 8}

The current bottom geomorphology of the Chang 8 reservoir presents an overall large-scale pattern that includes one convex area and one concave area. Convex belts are distributed in the southeast of the basin. Eastern areas, and the difference in elevation of the convex area is $>700 \mathrm{~m}$. 


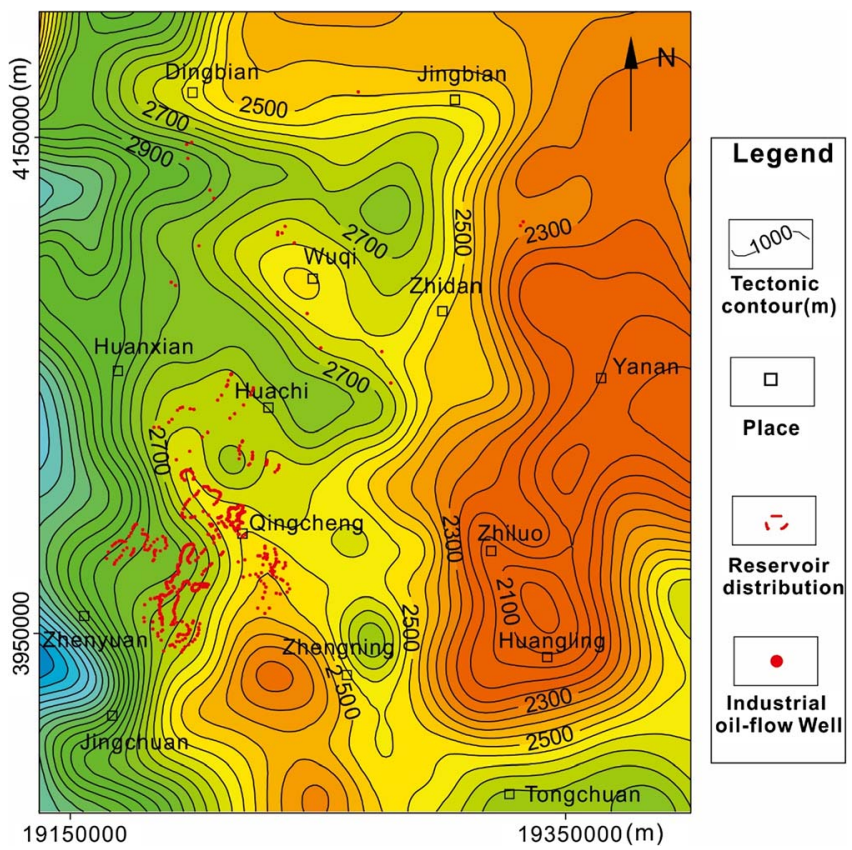

Fig. 7. Structural morphology of Chang 8 member bottom at the end of the Early Cretaceous and reservoir distribution of the Ordos Basin.

The area in the western part of the basin is a depression. Between the concave and convex sections are slope areas, whose structures change more gently. Additionally, it is obvious that in the entire slope setting, smaller, partially convex areas are developed, such as in the south-eastern region (Fig. 1c). It can be seen from Figure 6 that the Chang 8 reservoir remains almost completely distributed on the slope, where the structure changes relatively gently.

\subsection{Evolutionary characteristics and structure of the well-connected section C9-Jt600}

The structural features of the well-connected section, C9-Jt600, indicate that the tectonic position of the Yanchang Formation is gradually rising in the northeastern direction. The formation appears to exhibit a nearly single-dip structure. Meanwhile, the section of the well tie during the hydrocarbon generation period (i.e., the deepest period of burial at the end of the Late Cretaceous) is represented by a tectonic arch developed in region W47-Dt6254 (Fig. 8).

\subsection{Distribution of overpressure between Chang 7 and Chang 8 strata}

In the north-western and western Ordos Basin, there are two high-value zones of differential overpressure between Chang 8 and Chang 7 strata, with the overpressure ranging from 10-20 Mpa. If the Chang 7 member is the hydrocarbon source rock, then the high overpressure region is provided by the dynamic condition of downward movement of the Chang 7 oil source (Fig. 9).
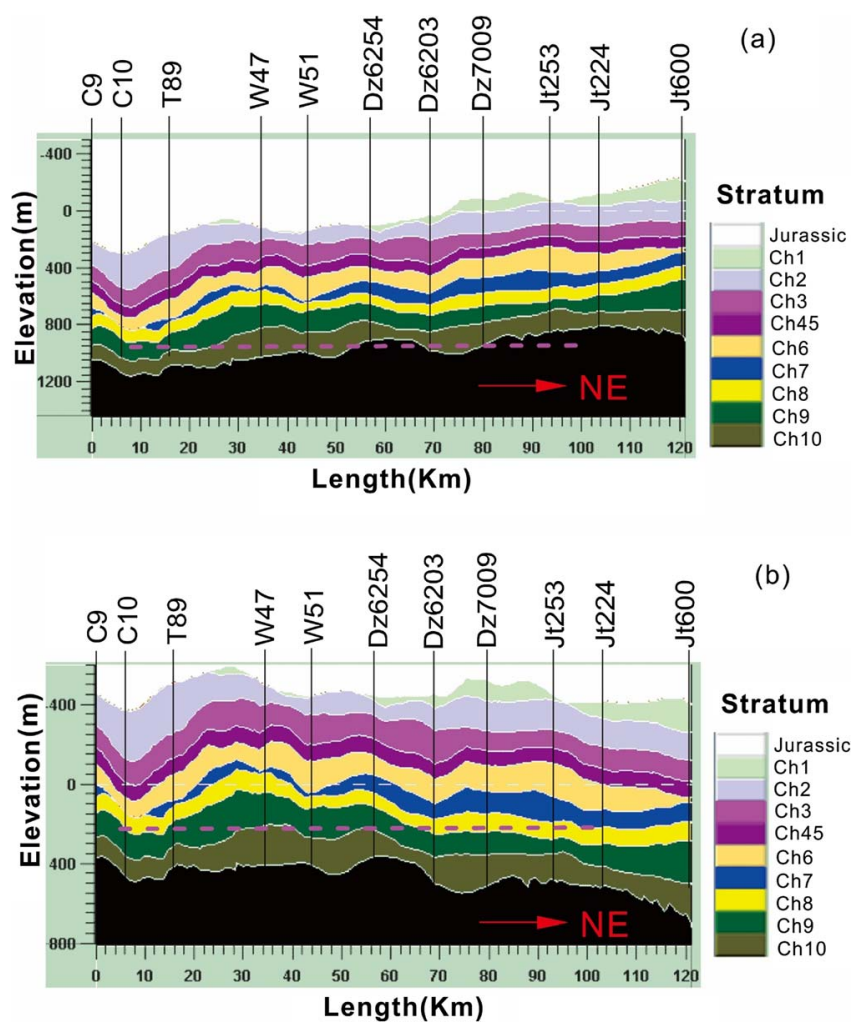

Fig. 8. Structural morphology of well connection profile in the Ordos Basin. (a) At the end of the Early Cretaceous; (b) At the end of the Middle Jurassic.

\subsection{Distribution of the sand-ground ratio in the Chang 8 member}

The higher sand-ground ratio of the Chang 8 member exhibits a zonal distribution, and generally features a northwest-southeast trend, revealing that sediments are mainly provided to the basin from the northeast and southwest. At present, explorations have shown that the Chang 8 reservoir is not completely distributed within the region with higher sand-ground ratios, but is found in the region with low sand-ground ratios. Recent studies have shown that a high-quality reservoir may have been formed in the palaeoslope background region during the sedimentation phase, including within the turbidite sand body (Fig. 10).

\section{Discussion}

\subsection{Distribution of oil reservoirs along gentle slopes of target layers during the hydrocarbon generation period}

Both the Chang 8 and Chang 6 oil reservoirs are located on the gentle slopes of a palaeohigh. The Chang 8 oil reservoirs are mostly distributed in the south-western part of the basin, while the Chang 6 oil reservoirs are mostly distributed 


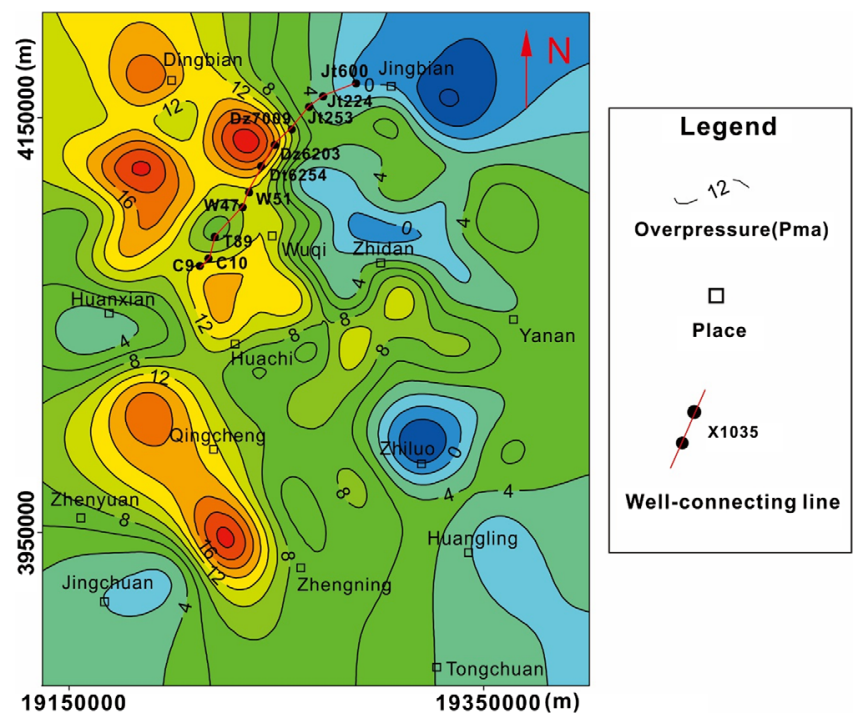

Fig. 9. Distribution characteristics of overpressure between Chang 7 and Chang 8 member in the Ordos Basin.

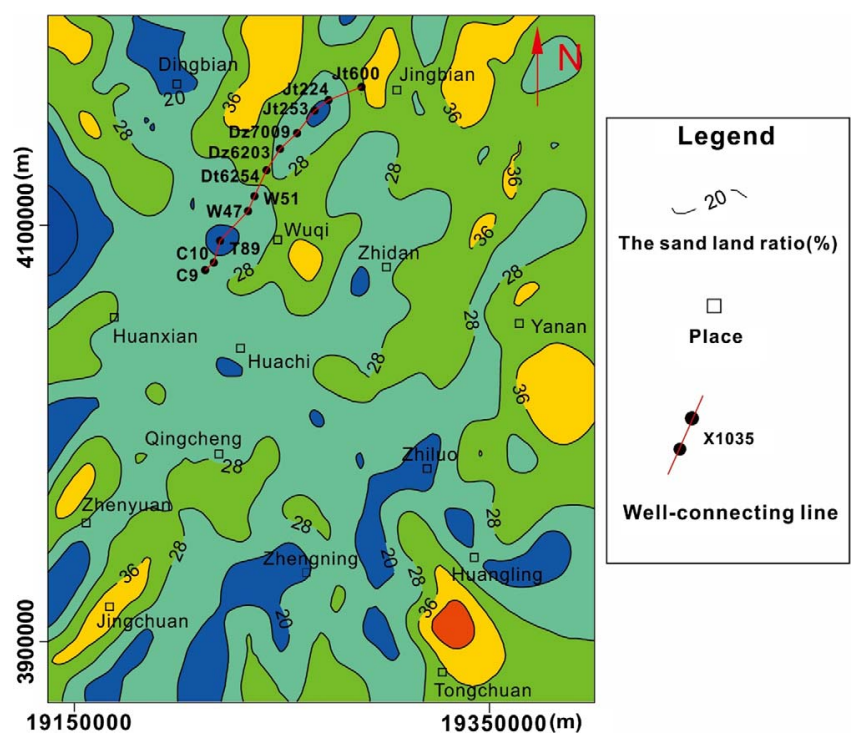

Fig. 10. Distribution of the sand-ground ratio in the Chang 8 member in the Ordos Basin.

in the north-eastern and south-western parts of the basin. This convincingly indicates that the bottom characteristics of the palaeohigh during the evolution of the lake basin in the Ordos Basin controlled the distribution of oil reservoirs, and that the distributions of different oil layer groups exhibit differential aggregation. The reason for this difference is the difference between the palaeostructures of the Chang 8 and Chang 6 reservoirs during the hydrocarbon generation period. This geological phenomenon initially attracted the attention of researchers from around the world. Now, researchers are gradually focusing on tight oil exploration in deep lacustrine areas (Figs. 5 and 6).

\subsection{Gentle slope of the target layers during the hydrocarbon generation period are necessary for the formation of a high-quality tight oil reservoir}

The high-quality reservoir condition in the Ordos Basin is one of the basic geological conditions necessary for tight oil accumulation. However, the formation of high-quality reservoirs of tight oil also requires certain structural conditions. The edges of sub-level depressions (or sedimentation centres) in lacustrine basins, the leading edge slopes of palaeo-highlands and the edges of palaeohighs are often the structural conditions needed for the formation of high-quality reservoirs (Yang et al., 2012). However, not until very recently has this understanding attracted much attention in the Ordos Basin. At present, studies on the characteristics of the bottom geomorphology of lake basin, especially quantitative studies, are very rare, and the recovery of the bottom geomorphology of the lake basin remains based on the traditional analyses of sedimentary facies, which only roughly reflect the outline of the bottom geomorphology of the lake basin. Regarding the nature of the Mesozoic lake basin on the stable craton in the Ordos Basin, it is difficult to clearly resolve important issues, such as the bottom geomorphology of the lake basin and the sedimentation slope break using the stratum filling structure and morphology revealed by current lithologic units, as well as the monotonous, almost parallel structure reflected by seismic data. This is also one of the reasons why the relationship between palaeostructures and oil reservoir distributions remain poorly understood. Basin simulation technologies provide an effective way for quantitatively investigating the characteristics of the bottom geomorphology of the lake basin, making it possible to further study the relationship between the bottom geomorphology and high-quality reservoir, and the underlying causes and distributions of high quality reservoirs (Figs. 5 and 6).

\subsection{Favourable structural traps allowed oil reservoir preservation in the current westward-inclined monoclines}

Taking the well tie section C9-Jt600 as an example, Temis2D v.4.3 was used to simulate the stratigraphic evolution of this section. The simulation results of the section of the well tie indicate that the C9-Jt600 well tie section shows the structural position of the current strata of the Yanchang Formation is gradually uplifted in the northeast direction, and the strata present an almost single-dip structure. However, during the hydrocarbon generation period (namely, the period when the strata were buried at the maximum depth, which was during the Late Cretaceous, the well tie section developed a large uplifted structure in the W47-Dt6254 region (Fig. 8).

The Chang 7 member of the Yanchang Formation in the Ordos Basin is the major hydrocarbon generation layer of the Mesozoic. In the period of maximum burial depth of the Yanchang Formation, the Chang 7 member had already begun to generate large quantities of hydrocarbon (Fig. 4). Oil and gas usually tend to migrate upward. Therefore, the hydrocarbons generated by Chang 7 hydrocarbon 
generation layer must have exhibited downward migration dynamics in order to gather and accumulate in the underlying Chang 8. In areas with large differences in pressure between Chang 7 and Chang 8 strata, hydrocarbons could have migrated and accumulated downward (assuming that reservoir conditions were also available) (Fig. 10). By using the logging data of acoustic time difference, it is possible to calculate the excess stratigraphic pressure at the maximum burial depth. For the W47-Dt6254 well tie zone, which has a relatively large anticlinal structure that developed at the end of the Late Cretaceous, when large quantities of hydrocarbons were generated, the excess pressure difference between Chang 7 and Chang 8 strata was relatively high at 4-10 MPa (Fig. 9). This excess pressure difference might have caused Chang 7 hydrocarbons to migrate downward. The migration channel would mainly have been the connected pores in the reservoir, and it was possible for the hydrocarbons to accumulate in the more favourable reservoir segments of the Chang 8 member. At the end of the Cretaceous, the Ordos Basin began to rise and no large fault systems were formed inside of the basin. Therefore, for the Mesozoic low-permeability and ultra-low-permeability reservoirs, the overall uplift-driven erosion was just a reduction of the fluid pressure in the reservoir, as the fluid in the reservoir of the Yanchang Formation was still essentially in a closed environment. Oil and gas reservoirs that had been formed could thus be well-preserved in the monoclinal oil reservoir of today.

The strata of the current Yanchang Formation present as a west-inclined monocline, with a dense reservoir lithology. This is also what has stifled the exploration of oil reservoirs in the Yanchang Formation for so long. The results of this study show that models of the palaeo-anticlinal structural setting of the Yanchang Formation during the high-volume hydrocarbon generation period, when controlled by this setting and combined with other reservoir forming conditions (e.g., downward migration and accumulation dynamics, reservoir, etc.), can effectively predict the tight oil distribution zones in the Ordos Basin.

\subsection{Tight oil exploration based on palaeostructure during the hydrocarbon generation period elucidates the relationship between the geological and causal mechanisms in hydrocarbon accumulation}

At present, the fundamental hydrocarbon generation conditions for tight oil in the Ordos Basin have been ascertained, and the effective allocation of hydrocarbon source rocks and other accumulation factors during the accumulation period will be the focus of future studies. Paying attention to the important role of structural factors (here, the bottom geomorphology of the lake basin) in the accumulation of tight oils makes it possible to directly discover and evaluate the sweet spot of tight oil. It has been suggested in previous studies that two major factors control the formation of sweet spots. First, maturity plays an important role in controlling the distribution of liquid hydrocarbon sweet spots in shale layer, and is the primary influencing factor. Second, under the current economic and technical conditions in China and other nations, a certain structural setting (i.e., one that is conducive to the long-term accumulation of oil and gas and to the development of natural fractures) and fluid flow are prerequisites for the formation of liquid hydrocarbon sweet spots in shale layers (Yang et al., 2015).

In the specific exploration practice, the area with paleotectonic background developed in the Chang 8 target layer in the hydrocarbon generation stage is the priority area. Within the scope of this area, combining with other reservoir forming geological conditions is a feasible exploration idea and method.

\section{Conclusion}

The area where the palaeotectonic background is developed in the Chang 8 target layer during the hydrocarbon generation stage is the priority area for exploration. Within this area, combining the palaeostructure with other reservoirforming geological conditions is a feasible exploration method. The target layer structure of the Chang 8 reservoir and its evolutionary characteristics indicated that the bottom convex structure (i.e., the nose-shaped, uplifted structure) is oil-rich. Most Chang 8 tight oil reservoirs are distributed on the slopes of both sides of the bottom convex structure. This structural slope belt is a necessary condition for the formation of high-quality reservoirs (such as turbidites).

The tectonic geomorphology of the concave and convex structure of the bottom of the Chang 8 target layer in each hydrocarbon generation period showed that the bottom convex structure was inherited and played a decisive role in the formation of large oil reservoirs in later stages. During the hydrocarbon generation period, this prominent, noseshaped uplift controlled the distribution of large oil fields, while the current structure has little relationship to the oil reservoirs. The palaeotectonic geomorphology of the target layers during the hydrocarbon generation period had an obvious control over the distribution of the reservoir.

The characteristics of lake basin bottom geomorphology during the accumulation period controlled the formation and distribution of large tight oil reservoirs. The palaeoslope and palaeo-uplift areas of the lake basin during the accumulation period were tight oil areas, which convincingly demonstrate that conditions for high-quality reservoir formation existed in this area. Combined with the favourable raw reservoir allocation and better subsequent diagenetic environment, this was an important area for the development of tight oil reservoirs.

It is useful to clarify the key factors controlling tight oil accumulation in the Ordos Basin, and reservoir conditions are clearly key to reservoir formation. In this study, the identification of the location of a high-quality reservoir and exploration of the relationship between its formation and the bottom geomorphology of lake basin were first pursued. A tight oil reservoir was evaluated within palaeoslope and uplift areas (i.e., high-quality reservoir formation areas), which is conducive to guiding changes in the 
exploration mind-set and enriching the theory of tight oil exploration.

Acknowledgments. The authors would like to acknowledge the editorial office of OGST and the reviewers for their comments and suggestions of this contribution. Thanks to professors $\mathrm{Qu}$ Hongjun and $\mathrm{Pu}$ Renhai from the department of geology of Northwestern University of China for their helpful suggestions during the revision of the paper. We thank the Research Institute of Changqing Oilfield, CNPC for software platform support.

\section{References}

Bai H., Pang X., Kuang L., Wan Z., Pang H., Wang X., Jia X., Song X. (2017) Depositional environment, hydrocarbon generation and expulsion potential of the middle Permian Pingdiquan source rocks based on geochemical analyses in the eastern Junggar Basin, NW China, Aust. J. Earth Sci. 64, 497-518.

Gao S., Ren Z. (2006) Restoration of eroded thickness and its influence on thermal evolution of Upper Paleozoic source rocks in Ordos Basin, Oil Gas Geol. 02, 180-186.

Guo S. (2010) The influence of the pre-existing topography on the depositionary systems, the development of the Lower Jurassic reservoirs and hydrocarbon accumulation in Central Western Ordos Basin, J. Petrol. Sci. Eng. 75, 129-134.

He Z. (2003) Evolution and oil and gas in Ordos Basin, Oil Industry Press, Beijing, China.

Hu T., Pang X., Wang X., Pang H., Liu Y., Wang Y., Tang L., Chen L., Pan Z., Xu J., Pang Y. (2016) Tight oil play characterisation: the lower-middle Permian Lucaogou Formation in the Jimusar Sag, Junggar Basin, Northwest China, Austral. J. Earth Sci. 63, 349-365.

Lai J., Wang G., Chai Y., Ran Y. (2016) Prediction of diagenetic facies using well logs: Evidences from upper triassic yanchang formation Chang 8 sandstones in Jiyuan Region, Ordos Basin, China, Oil Gas Sci. Technol. - Rev. IFP Energies nouvelles $\mathbf{7 1}, 34$.

Liu J., Xie S., Liu K., Yuan W. (1986) Evolution stacking and hydrocarbon potential of the Ordos Basin, Oil Gas Geol. 7, 356-367.

Ren Z., Li W., Liang Y., Wu X., Yu Q., Ren L., Wang W. (2014) Tight oil reservoir formation conditions and main controlling factors of Yanchang Formation in southeastern Ordos Basin, Oil Gas Geol. 35, 190-198.
Ren Z., Yu Q., Cui J., Qi K., Chen Z., Cao Z., Yang P. (2017) Thermal history and its controls on oil and gas of the Ordos Basin, Earth Sci. Front. 24, 137-148. (China University of Geosciences (Beijing); Peking University).

Sun G., Liu J., Liu K., Yuan W. (1985) Evolution of a major mesozoic continental basin within huabei plate and its geodynamic seting, Oil Gas Geol. 6, 280-287+350.

Xu Q., Shi W., Xie X., Manger W., McGuire P., Zhang X., Wang R., Xu Z. (2016) Deep-lacustrine sandy debrites and turbidites in the lower Triassic Yanchang Formation, southeast Ordos Basin, central China: Facies distribution and reservoir quality, Mar. Pet. Geol. 77, 1095-1107.

Yang H., Fu J., He H., Liu X., Zhang Z., Deng X. (2012) Formation and distribution of large low-permeability lithologic oil regions in Huaqing, Ordos Basin, Petrol. Explor. Dev. 39, 641-648.

Yang H., Liang X.W., Niu X.B., Feng S.B., You Y. (2017) Geological conditions for continental tight oil formation and the main controlling factors for the enrichment: A case of Chang 7 Member, Triassic Yanchang Formation, Ordos Basin, NW China, Petrol. Explor. Dev. 44, 12-20.

Yang H., Liu X., Zhang C., Han T., Hui X. (2007) The main controlling factors and distribution of low permeability lithologic reservoirs of Triassic Yanchang Formation in Ordos Basin, Lithol. Reserv. 19, 1-6.

Yang W., Liu G., Liu X., Feng Y., Du Y., Cheng D. (2013) The accumulation mechanism and accumulation models of oil in low permeability reservoir of Yanchang Formation in Longdong Area, Ordos Basin, Earth Sci. Front. 20, 132-139. (China University of Geosciences (Beijing); Peking University).

Yang Z., Hou L., Tao S., Cui J., Wu S., Lin S., Pan S. (2015) Formation conditions and "sweet spot" evaluation of tight oil and shale oil, Petrol. Explor. Dev. 42, 555-565.

Yao J.L., Deng X.Q., Zhao Y.D., Han T.Y., Chu M.J., Pang J.L. (2013) Characteristics of tight oil in Triassic Yanchang Formation, Ordos Basin, Petrol. Explor. Dev. 02, 150-158.

Ye L. (1983) North China platform sedimentary formation, Science Press, Beijing, China.

Zhao J., Bai Y., Cao Q., Er C. (2012) Quasi-continuous hydrocarbon accumulation: A new pattern for large tight sand oilfields in the Ordos, Oil Gas Geol. 33, 811-827.

Zhao J., Yang X., Wu F., Shi B. (2006) Controlling of uplifts on the Triassic petroleum accumulation and distribution in North Shaanxi Slope, Ordos Basin, Acta Geol. Sin. 80, 648-655. 